\title{
Growth Behavior of a Mechanically Long Fatigue Crack in an FeCrNiMnCo High Entropy Alloy: A Comparison with an Austenitic Stainless Steel
}

\author{
Shunsuke MIZUMACHI, ${ }^{1)}$ Motomichi KOYAMA, ${ }^{21 *}$ Yoshihiro FUKUSHIMA ${ }^{1)}$ and Kaneaki TSUZAKI ${ }^{1)}$ \\ 1) Department of Mechanical Engineering, Kyushu University, 744 Motooka, Nishi-ku, Fukuoka, 819-0395 Japan. \\ 2) Institute for Materials Research, Tohoku University, 2-1-1 Katahira, Aoba-ku, Sendai, 980-8577 Japan.
}

(Received on April 9, 2019; accepted on July 17, 2019; originally published in Tetsu-to-Hagané, Vol. 105, 2019, No. 2, pp. 215-221)

\begin{abstract}
The fatigue crack growth characteristics of an Fe20Cr20Ni20Mn20Co high-entropy alloy (HEA) were investigated by $\Delta K$ increasing compact tension test in comparison with SUS316L. The fatigue crack growth rate of the HEA was lower than that of the SUS316L. The predominant crack growth path was the grain interior for both alloys. A difference was observed in the crack roughness; i.e., the fatigue crack growth path of the HEA was more distinctly deflected than that of the SUS316L. This indicates that roughnessinduced crack closure is a key factor reducing the crack growth rate of the HEA. Another key factor is the noncrystallographic transgranular crack growth mechanism. The SUS316L exhibited crack growth via crack blunting/re-sharpening, while the HEA exhibited transgranular crack growth associated with dislocation substructure alignment.
\end{abstract}

KEY WORDS: high-entropy alloy; austenitic steel; fatigue; compact tension test; microstructure evolution.

\section{Introduction}

Metals have been strengthened by controlling the distribution/amount of lattice defects, microstructure interfaces, and solution elements. In this regard, focusing on the effect of solution elements, high-entropy alloys (HEA) that are equiatomic or contain large amounts of various elements have drawn attention. HEAs have an excellent strengthductility combination ${ }^{1)}$ and high fracture resistance. ${ }^{2}$ In particular, the HEA containing 20 at. $\% \mathrm{Fe}, \mathrm{Cr}, \mathrm{Ni}, \mathrm{Mn}$, and $\mathrm{Co}$, which is referred to as an equiatomic HEA, shows outstanding cryogenic fracture toughness. ${ }^{2}$ Moreover, HEAs show significant solid solution strengthening resulting from lattice distortion because of the multiple and large amount of solution elements. Although various mechanical properties of HEAs have been reported, ${ }^{1-7)}$ there are few reports on the fatigue properties. Because fatigue fracture accounts for approximately $80 \%$ of accidental failures in structural materials, understanding the fatigue mechanisms of HEAs is important for practical use. In 2017, compact tension (CT) tests were performed on an equiatomic HEA to evaluate the fatigue crack growth rate. ${ }^{8)}$ The reference materials were austenitic stainless steels (SUS316L, SUS304L, etc.), which have a similar crystal structure and similar physical properties to the HEA. In the previous study, the threshold stress intensity factor range $\left(\Delta K_{\text {th }}\right)$ of the HEA was higher than that of austenitic stainless steels. Besides, in the Paris

\footnotetext{
* Corresponding author: E-mail: koyama@imr.tohoku.ac.jp DOI: https://doi.org/10.2355/isijinternational.ISIJINT-2019-230
}

law regime, where the crack grows stably, the fatigue crack growth behavior of the HEA was reported to be similar compared to that of the austenitic stainless steels, however, the fatigue crack growth rates showed a variety depending on the stress intensity factor range $(\Delta K)$. Therefore, comparative studies on fatigue crack growth behaviors at different the fatigue crack lengths or $\Delta K$ values must be investigated in detail. Moreover, the effects of the high entropy on the deformation microstructure remain unclear. In this study, the fatigue crack growth characteristics and associated deformation microstructures of an Fe20Cr20Ni20Mn20Co (at.\%) HEA were investigated via CT testing with an increase of $\Delta K$ in comparison with SUS316L. On the basis of the results, we discuss the possibility of improving the fatigue crack growth property using the high-entropy concept.

\section{Experimental Procedure}

\subsection{Materials}

In this study, we prepared an Fe20Cr20Ni20Mn20Co (at.\%) HEA and SUS316L. Both alloys had only the facecentered cubic phase, ${ }^{9)}$ and they did not exhibit deformationinduced martensitic transformation at room temperature. The chemical compositions and Vickers hardness values are presented in Table 1. Vickers hardness tests were performed with a load of $19.6 \mathrm{~N}$, at which the indent appeared across multiple grains. We measured 15 points for each alloy and calculated the average of 13 values, excluding the maximum and minimum values. An ingot of the HEA was prepared via vacuum induction melting and hot-rolled 
Table 1. Chemical compositions (mass $\%$ ) and Vickers hardness $\left(\mathrm{kgf} / \mathrm{mm}^{2}\right)$ of the alloys used.

\begin{tabular}{ccccccccccccccc}
\hline & $\mathrm{Fe}$ & $\mathrm{Mn}$ & $\mathrm{Ni}$ & $\mathrm{Co}$ & $\mathrm{Cr}$ & $\mathrm{Mo}$ & $\mathrm{C}$ & $\mathrm{Si}$ & $\mathrm{P}$ & $\mathrm{S}$ & $\mathrm{N}$ & $\mathrm{O}$ & $\mathrm{Al}$ & $\mathrm{HV}$ \\
\hline HEA & 20.90 & 19.77 & 20.21 & 20.85 & 18.23 & - & 0.002 & - & 0.002 & 0.006 & 0.0065 & 0.007 & 0.018 & 141 \\
SUS316L & 65.0 & 0.84 & 12.1 & - & 17.9 & 2.06 & 0.012 & 0.48 & 0.027 & $<0.002$ & 0.033 & 0.002 & 0.003 & 135 \\
\hline
\end{tabular}
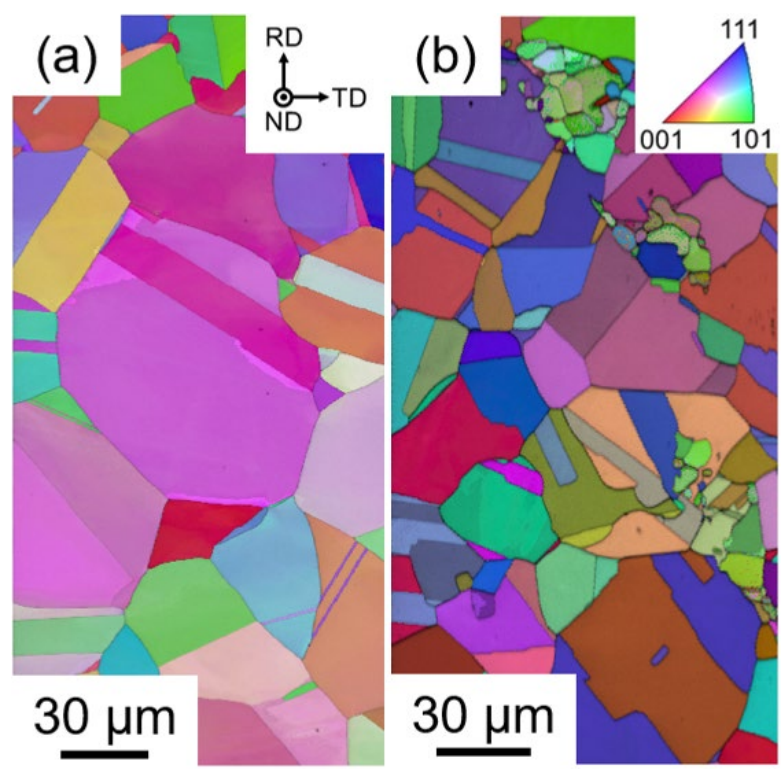

Fig. 1. RD-inverse pole figure (IPF) map coupled with image quality (IQ) data for the initial microstructures of (a) HEA and (b) SUS316L. The magnification is not identical in (a) and (b). (Online version in color.)

at $1000^{\circ} \mathrm{C}$, followed by homogenization at $1200^{\circ} \mathrm{C}$ for $2 \mathrm{~h}$ in an Ar atmosphere and furnace cooling. The homogenized bars were hot-rolled again to reduce the thickness from 60 to $20 \mathrm{~mm}$ and air-cooled. The rolled bars were solutiontreated at $800^{\circ} \mathrm{C}$ in an air atmosphere for $1 \mathrm{~h}$, followed by water-quenching. We also prepared commercially available solution-treated SUS316L. Figure 1 shows the initial structure of both alloys.

\subsection{Fatigue Crack Growth Test}

We performed CT tests according to ASTM-E647 ${ }^{10)}$ with a constant frequency of $f=25 \mathrm{~Hz}$ and a constant stress ratio of $R=0.1$ in the region of stress intensity factor range $(\Delta K)$ of approximately 15 to $30 \mathrm{MPa} \mathrm{m} \mathrm{m}^{1 / 2}$ at $23^{\circ} \mathrm{C}$ in air. Figure 2 shows the shapes of the CT specimens: their gauge dimensions were $50.8 \mathrm{~mm}$ (width), $10 \mathrm{~mm}$ (thickness), and $10 \mathrm{~mm}$ (machined notch length). The loading direction was parallel to the rolling direction (RD). The crack length was calculated using the crack opening displacement (COD) measured by a clip gauge. A test involving the increase of $\Delta K$ was performed after introducing a pre-crack with the same $f$ and $R$ as those for the main experiment.

After the CT tests, we observed the fracture surface using scanning electron microscopy (SEM). The observation was performed at $15 \mathrm{kV}$ with a working distance (WD) of 9-10 $\mathrm{mm}$. Microstructure observations were performed via electron backscatter diffraction (EBSD) analysis and electron channeling contrast imaging (ECCI) after the CT specimens were cut through the middle and mechanically polished using colloidal silica to remove the damaged layers. EBSD (a) thickness $=10$

(b)
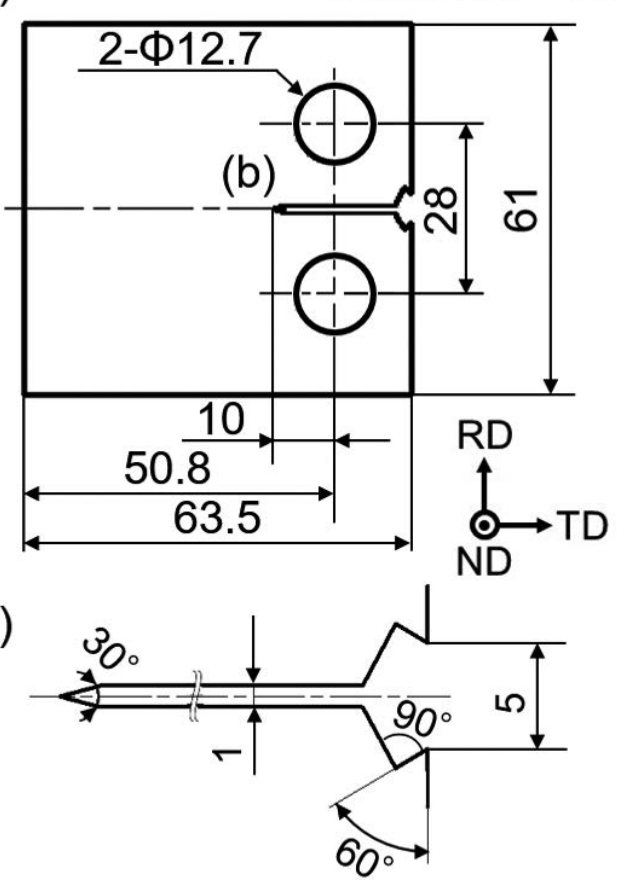

Fig. 2. Shapes and dimensions of (a) the specimen and (b) the notch (mm).

analysis was performed at $20 \mathrm{kV}$ with $\mathrm{WD}=15 \mathrm{~mm}$ and a beam step size of $500 \mathrm{~nm}$. ECCI was performed at $30 \mathrm{kV}$ with WD $=3-4 \mathrm{~mm}$.

\section{Results}

\subsection{Fatigue Crack Growth Test}

Figure 3 shows the relationship between the fatigue crack growth rate $(\mathrm{d} a / \mathrm{d} N)$ and $\Delta K$ for the HEA and the SUS316L. The fatigue crack growth rate of the HEA was lower than that of the SUS316L in the present $\Delta K$ range. In particular, the difference in the fatigue crack growth rates between the two alloys below $\Delta K=22 \mathrm{MPa} \cdot \mathrm{m}^{1 / 2}$ was remarkable.

\subsection{Observation of Microstructure}

\subsubsection{SUS316L}

Figure 4 shows SEM images of the SUS316L in a region corresponding to approximately $\Delta K=18 \mathrm{MPa} \cdot \mathrm{m}^{1 / 2}$ where a large difference in fatigue crack growth rate between the two alloys was observed. Hereinafter, all the observation regions correspond to $\Delta K=18 \mathrm{MPa} \cdot \mathrm{m}^{1 / 2}$. The fracture surface of the SUS316L exhibited two characteristic features: a relatively-flat surface (Fig. 4(b)) and a non-flat surface with a striation-like pattern (Fig. 4(c)). The spacing of the striation-like pattern was approximately $1 \mu \mathrm{m}$, which did not correspond to the fatigue crack growth rate $\left(3.2 \times 10^{-2}\right.$ $\mu \mathrm{m} /$ cycle). Moreover, most of the fracture surfaces were non-flat ones. 


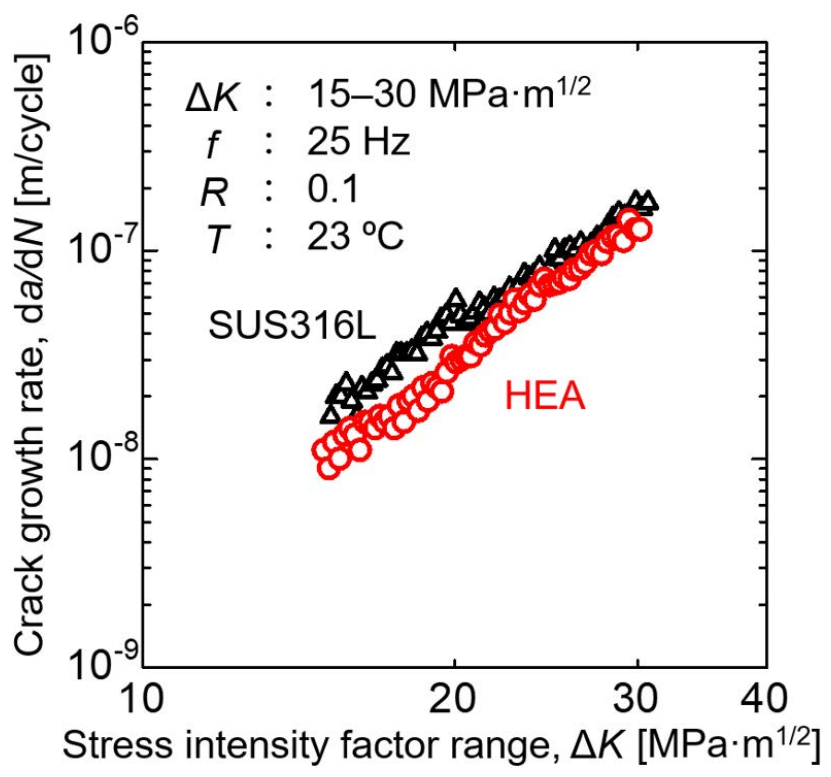

Fig. 3. Fatigue crack growth rates plotted with respect to the stress intensity factor range. The HEA shows lower growth rates than the SUS316L, especially in the lowstress intensity factor range. (Online version in color.)

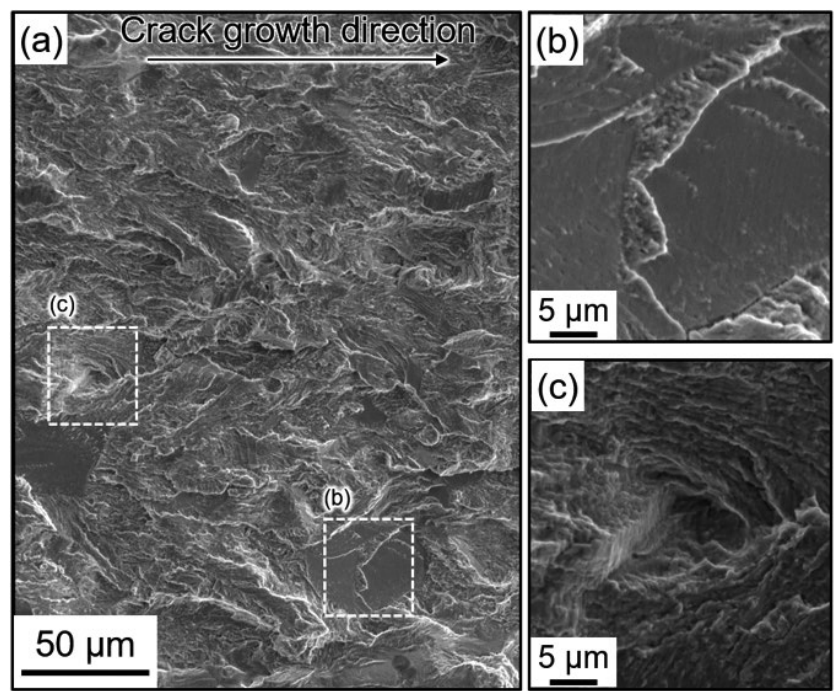

Fig. 4. SE images of the fracture surface of SUS316L at $\Delta K=18$ $\mathrm{MPa} \cdot \mathrm{m}^{1 / 2}$, where the crack growth rate was $3.2 \times 10^{-2} \mu \mathrm{m} /$ cycle (Fig. 3). (a) Overview of the fracture surface consisting of portions with the following characteristics: (b) a relatively-flat surface and (c) a non-flat surface with a striation-like pattern.

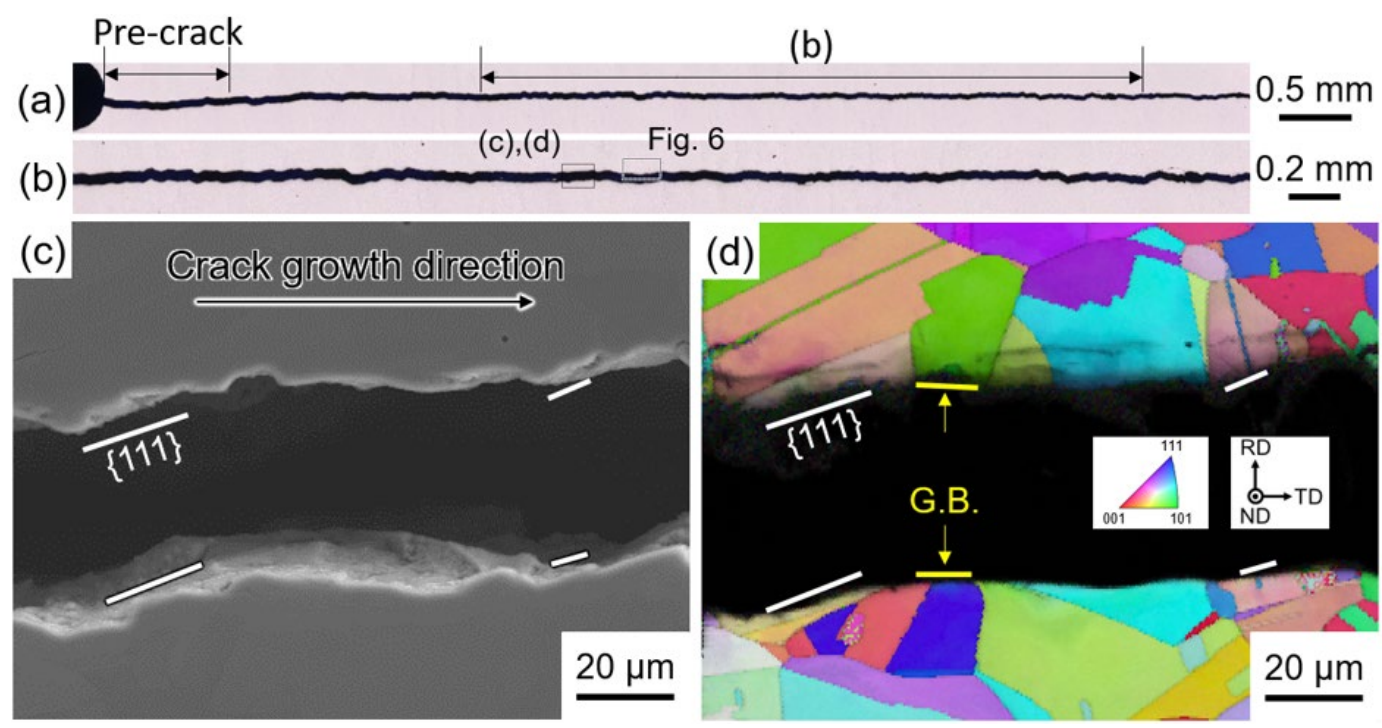

Fig. 5. Light microscopic images: (a) low-magnification image for the range of $\Delta K=15-21 \mathrm{MPa} \cdot \mathrm{m}^{1 / 2}$; (b) high-magnification image for the range of $\Delta K=16-20 \mathrm{MPa} \cdot \mathrm{m}^{1 / 2}$. (c) SE image and (d) RD-IPF + IQ map around the fracture path of SUS316L at $\Delta K=18 \mathrm{MPa} \cdot \mathrm{m}^{1 / 2}$. The yellow arrows indicate the intergranular crack growth regions. The white lines indicate the $\{111\}$ slip traces for each grain. The crack propagated mostly within the grains. The observation was made on the cross-sectional area at the mid-thickness of the CT specimen. (Online version in color.)

Figure 5 shows a light micrograph, a secondary-electron (SE) image, and the EBSD analysis results for the SUS316L. As shown in Figs. 5(c) and 5(d), in the SUS316L, most of the main crack propagated transgranularly around $\Delta K=18$ $\mathrm{MPa} \cdot \mathrm{m}^{1 / 2}$. The white lines in Figs. 5(c) and 5(d) indicate the traces of the $\{111\}$ plane. Part of the main crack propagation path of the SUS316L was along the $\{111\}$ plane. Additionally, intergranular crack propagation was observed, as indicated by the yellow lines and the arrows.

Figure 6 shows ECC images of the area near the main crack in the SUS316L. Sharp plate-like deformation twins were observed near $10 \mu \mathrm{m}$, far from the fracture surface; however, the main crack did not propagate along deformation twins. As shown in Fig. 6(c), a dislocation substructure similar to a dislocation cell with a diameter of approximately $1 \mu \mathrm{m}$ formed in the vicinity of the main crack.

\subsubsection{HEA}

Figure 7 shows SEM images of the HEA. The fracture surface of the HEA exhibited three characteristics: a relatively-flat intergranular fracture feature (Fig. 7(b)), a relatively-flat transgranular surface (Fig. 7(c)), and a nonflat surface with a striation-like pattern (Fig. 7(d)). Similar to the SUS316L, the spacing of the striation-like pattern was approximately $1 \mu \mathrm{m}$, which did not correspond to the fatigue crack growth rate $\left(1.8 \times 10^{-2} \mu \mathrm{m} /\right.$ cycle $)$. Moreover, most of the fracture surfaces were non-flat ones. 

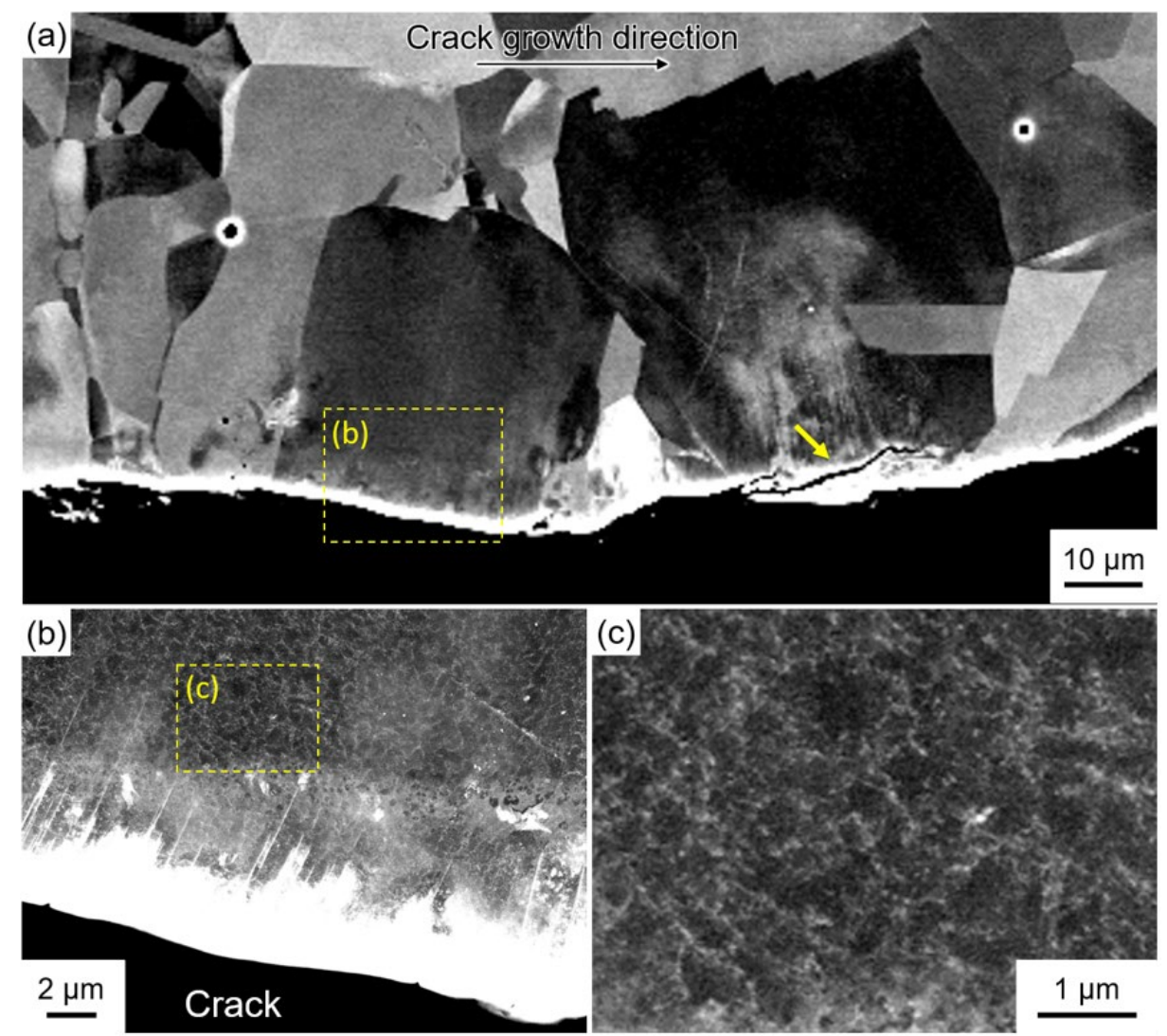

Fig. 6. ECC images around the fracture path of SUS316L at $\Delta K=18 \mathrm{MPa} \cdot \mathrm{m}^{1 / 2}$. (a) Low-magnification image of the area indicated in Fig. 5(b). The yellow arrow indicates a secondary crack. (b) Medium-magnification image of the region near the main crack surface. The sharp white lines indicate deformation twins, and dislocation cells are observed. (c) High-magnification image showing the dislocation cell structure with a size of approximately 1 $\mu \mathrm{m}$. (Online version in color.)

Figure 8 shows a light micrograph, an SE image, and the EBSD analysis results for the HEA. As shown in Figs. 8(c) and $8(\mathrm{~d})$, most of the main crack in the HEA propagated transgranularly around $\Delta K=18 \mathrm{MPa} \cdot \mathrm{m}^{1 / 2}$. However, comparing Figs. 5(c) and 5(d) with Figs. 8(c) and 8(d) reveals that the fatigue crack growth path of the HEA was distinctly deflected compared with that of the SUS316L. Figure 9 shows the relationship between the ratio of the actual crack length to the projected crack length and the stress intensity factor range for the HEA and the SUS316L. Here, $\mathrm{a}_{\mathrm{ac}}$ represents the crack length along the fracture surface, while $\mathrm{a}_{\mathrm{pr}}$ is the crack length projected in the direction perpendicular to the loading direction. This result quantitatively indicates that the degree of the deflection in the HEA was larger than that in the SUS316L. The white lines in Figs. 8(c) and 8(d) indicate the trace of the $\{111\}$ plane. Part of the main crack propagation path of the HEA was along the $\{111\}$ plane. Additionally, intergranular crack propagation was observed, as indicated by the yellow lines and the arrows. Figs. 8(c) and $8(\mathrm{~d})$ show the deflected crack growth path, which was not along the annealing twin boundary and the $\{111\}$ plane in the grain.

Figure 10 shows ECC images of the region surrounded by the dotted line in Fig. 8(c). This region is in the vicinity of the deflected part of the main crack that was not along the annealing twin boundary and the $\{111\}$ plane. Sharp plate-like deformation twins were observed around $10 \mu \mathrm{m}$, far from the fracture surface; however, the main crack did not propagate along the deformation twins. Moreover, the

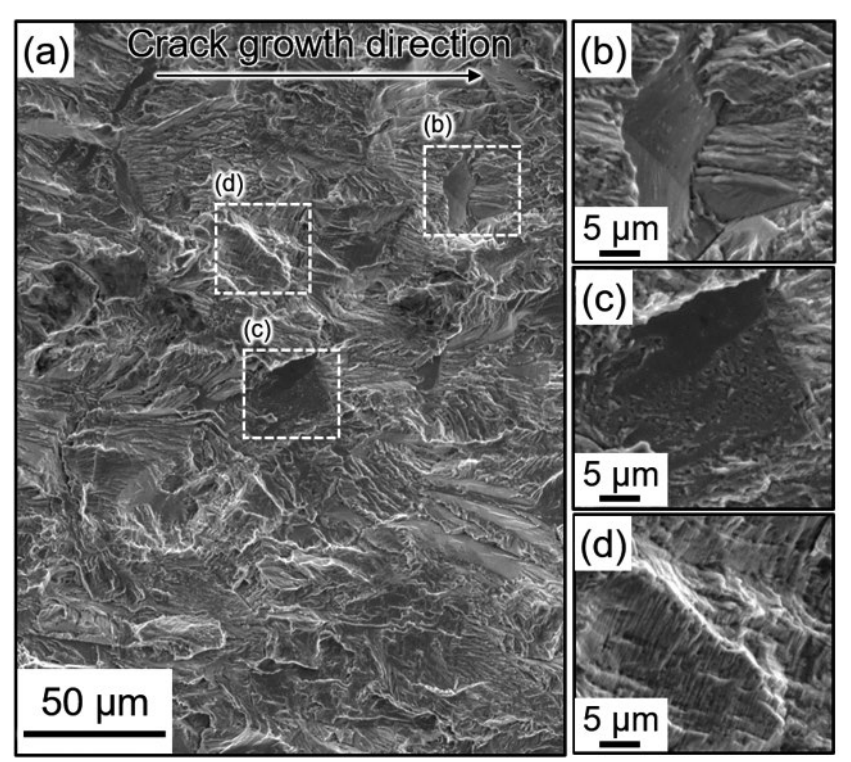

Fig. 7. SE images of fracture surface of HEA at $\Delta K=18$ $\mathrm{MPa} \cdot \mathrm{m}^{1 / 2}$, where the crack growth rate was $1.8 \times 10^{-2} \mu \mathrm{m} /$ cycle (Fig. 3). (a) Overview of the fracture surface consisting of portions with the following characteristics: (b) a relatively-flat intergranular fracture surface (c) a relatively-flat transgranular surface, and (d) a non-flat surface with a striation-like pattern.

deformation-twin probability for the HEA was lower than that for the SUS316L. As shown in Figs. 10(b) and 10(c), a dislocation cell-like microstructure with a diameter of 


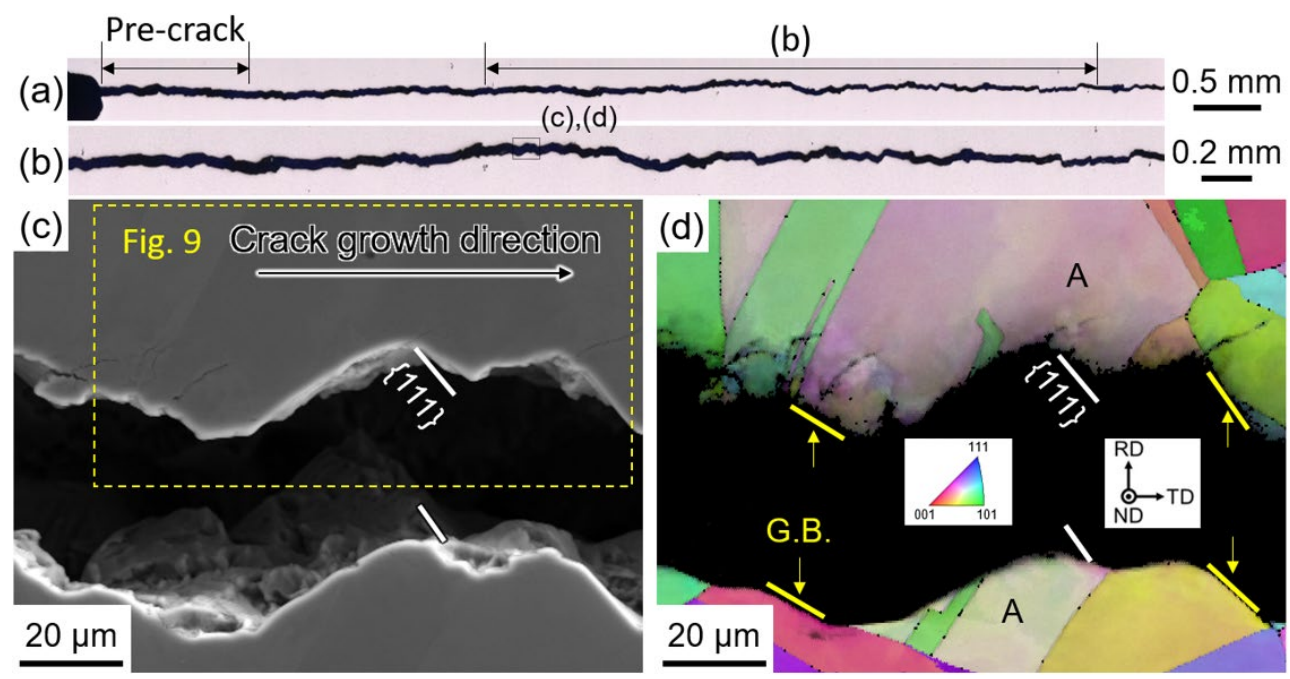

Fig. 8. Light microscopic images: (a) low-magnification image for the range of $\Delta K=15-21 \mathrm{MPa} \cdot \mathrm{m}^{1 / 2}$; (b) high-magnification image for the range of $\Delta K=16-20 \mathrm{MPa} \cdot \mathrm{m}^{1 / 2}$. (c) SE image and (d) TD-IPF + IQ map for the region around the fracture path of the HEA at $\Delta K=18 \mathrm{MPa} \cdot \mathrm{m}^{1 / 2}$. The yellow arrows indicate the intergranular crack growth regions. The white lines indicate the $\{111\}$ slip traces for grain A. The crack propagated mostly within the grains. The observation was made on the cross-sectional area at the mid-thickness of the CT specimen. (Online version in color.)

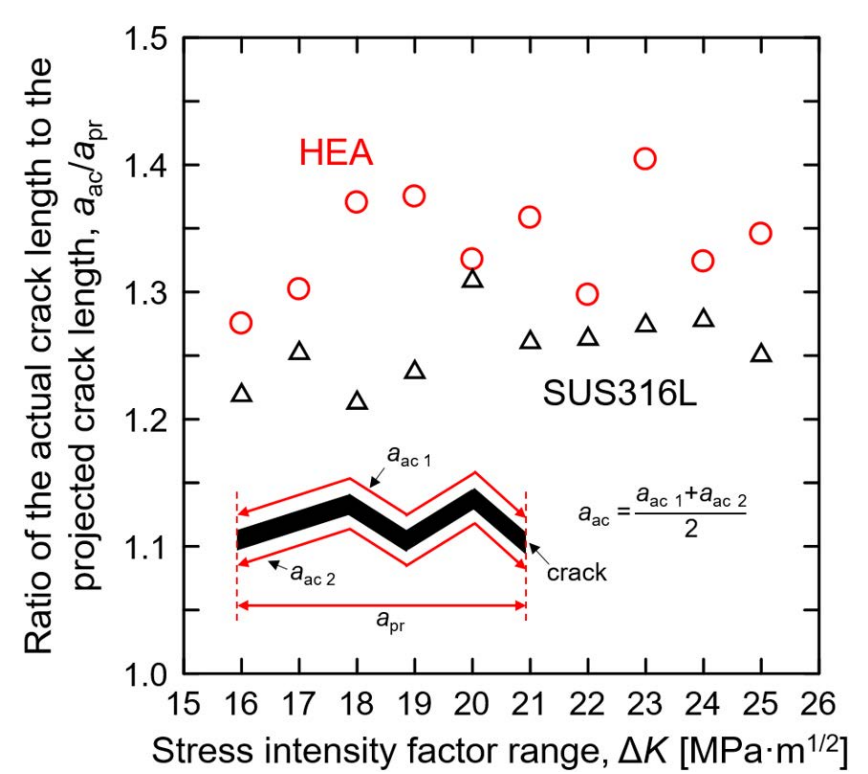

Fig. 9. Ratio of the actual crack length to the projected crack length plotted against the stress intensity factor range. The HEA exhibits a higher ratio than the SUS316L. The actual crack length was not measured in the $\Delta K$ region over 26 $\mathrm{MPa} \cdot \mathrm{m}^{1 / 2}$, because the crack length could not be clearly defined, owing to the crack branching and wear of the crack surfaces. (Online version in color.)

approximately $1 \mu \mathrm{m}$ formed in the vicinity of the main crack. Here, the crack growth behavior of the secondary crack is indicated by the yellow arrow. It is likely that the secondary crack exhibited similar behavior to the main crack growth with regard to the crack deflection. This secondary crack was parallel to the $\{111\}$ plane until it was approximately $3 \mu \mathrm{m}$ from the crack surface, and then it gradually deflected in the 2 o'clock direction, resulting in a curved crack with a length of approximately $15 \mu \mathrm{m}$.

Table 2 shows the area fractions of the flat fracture (facet fracture) surfaces of the SUS316L and the HEA obtained via fractography. According to the results, the fraction of flat fracture surface in the two alloys were approximately the same $(9 \%)$, namely, the fraction of non-flat fracture surface in the two alloys were also approximately the same (91\%).

\section{Discussion}

\subsection{Factors Affecting the Fatigue Crack Growth Rate}

The fatigue crack growth rate of the HEA was lower than that of the SUS316L. Here, we note crack closure effects that have been recognized as a primary factor increasing the fatigue crack growth resistance. ${ }^{11)}$ In particular, plasticityinduced crack closure and roughness-induced crack closure can occur under metal fatigue. Plasticity-induced crack closure is attributed to a plastic strain evolution at the crack tip during crack opening. The plastic strain evolution and subsequent crack propagation result in crack plane displacement at the crack wake. The crack surface displacement causes early crack surface contact during the unloading process, giving rise to a residual compressive stress field around the crack surface. Roughness-induced crack closure is derived from deflected crack growth. ${ }^{12-14)}$ A geometrical effect of the crack surface roughness causes early crack surface contact, yielding compressive stress during the unloading process. Comparison between Figs. 5 and 8 reveals that the fatigue crack propagation path of the HEA was deflected more distinctly than that of the SUS316L. Hence, the effect of roughness-induced crack closure was larger in the HEA than in the SUS316L. The roughness effect reduced the driving force for crack propagation, decelerating the crack growth in the HEA. Moreover, we suggest the following effects of the deflected crack on the crack growth rate. ${ }^{11)}$

(1) Because the stress intensity factor at the crack tip are divided into two components (Modes I and II), the crack deflection increased the remote load required for the crack propagation with the blunting/re-sharpening mechanism.

(2) Because the measured crack length was the projected length in the test, the growth rate of the deflected crack was lower than that of the straight crack. 

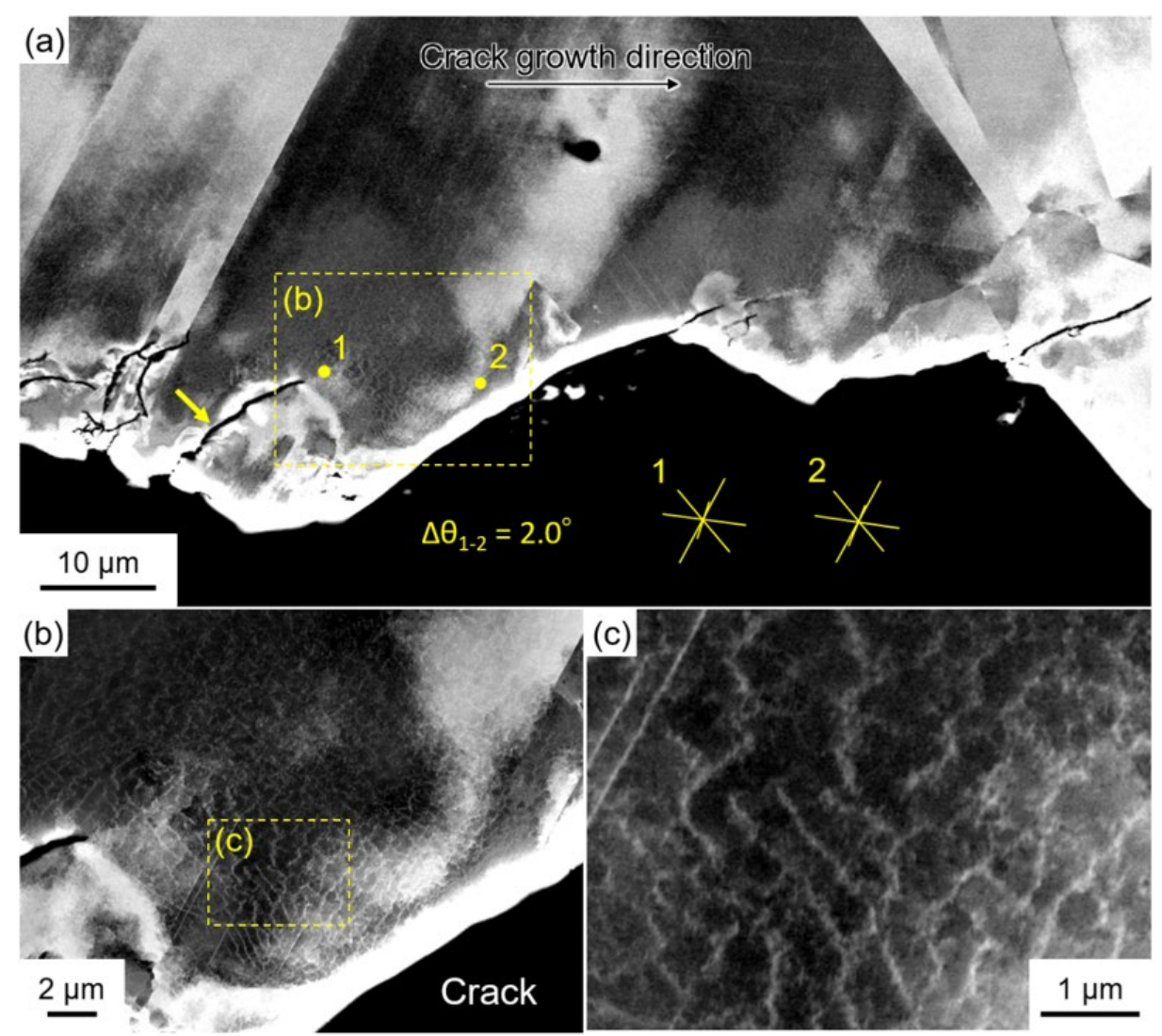

Fig. 10. ECC images of the region around the fracture path of the HEA at $\Delta K=18 \mathrm{MPa} \cdot \mathrm{m}^{1 / 2}$. (a) Low-magnification image of the area indicated in Fig. 8(c). The yellow arrow indicates a secondary crack. The yellow lines indicate the $\{111\}$ traces for points 1 and 2 . The misorientation between these two points is $2.0^{\circ}$. (b) Mediummagnification image of the region near the secondary crack tip and the main crack surface. The sharp white lines indicate deformation twins, and dislocation cells are observed. (c) High-magnification image showing the dislocation cell structure with a size of approximately $1 \mu \mathrm{m}$. (Online version in color.)

Table 2. Fraction of two fracture surface modes (\%) at $\Delta K=18$ $\mathrm{MPa} \cdot \mathrm{m}^{1 / 2}$. The total observation area for the SUS316L was $49330 \mu \mathrm{m}^{2}$, and that for the HEA was $49024 \mu \mathrm{m}^{2}$.

\begin{tabular}{ccc}
\hline & Facet fracture & others \\
\hline SUS316L & 8.7 & 91.3 \\
HEA & 8.8 & 91.2 \\
\hline
\end{tabular}

Accordingly, the deflected crack propagation path is considered to be the factor decreasing the crack growth rate.

\subsection{Reason for Crack Deflection in HEA}

As mentioned previously, the main crack of the HEA was deflected. Specifically, the main crack propagated along microstructural interfaces such as grain boundaries $^{8,15)}$ and twin boundaries, ${ }^{16,17)}$ resulting in facets on the fracture surface, as shown in Figs. 7(b) and 7(c). Another factor causing the facets was crack propagation along the slip plane within the grain interior. ${ }^{18,19)}$ The fractions of the facet fracture surface at $\Delta K=18 \mathrm{MPa} \cdot \mathrm{m}^{1 / 2}$ for both alloys are presented in Table 2. The fraction of the facet fracture surface exhibited no significant difference between the two alloys (approximately 9\%), and the major portion of the fracture surface showed non-facet fracture. This indicates that the growth path of the deflected crack in the HEA involved a larger fraction of the non-facet fracture surface than that in the SUS316L.
The transgranular fatigue crack in the SUS316L mainly propagated perpendicular to the load direction. This is because the fatigue crack in the SUS316L propagated through blunting and re-sharpening. ${ }^{20)}$ However, striations, which are involved in the crack blunting and re-sharpening process, were not observed at $\Delta K=18 \mathrm{MPa} \cdot \mathrm{m}^{1 / 2}$. Generally, when the crack growth rate is outside the range of $0.1-1 \mu \mathrm{m} /$ cycle, striations corresponding to fatigue crack growth rates do not appear. ${ }^{21)}$ Therefore, the present results do not contradict conventional results.

On the other hand, the crack growth path in the HEA was more frequently deflected than that in the SUS316L (Fig. 8), although crack propagation perpendicular to the loading direction was also observed in the HEA. Here we note the transgranular deflected crack growth that was not along the slip plane in the HEA (Fig. 10). The main and secondary cracks shown in Fig. 10 propagated in the same grain, and their crack surfaces were curved and were not along a specific crystallographic plane. Clear dislocation walls were formed near the crack surface (Figs. 10(b) and 10(c)), and the crack deflection may have been caused by crack propagation along the dislocation substructure. That is, the crack propagated along cell walls with a diameter of approximately $1 \mu \mathrm{m}$, which could have resulted in macroscopic crack deflection at the grain scale. Fatigue crack propagation along the dislocation walls was observed in pure Fe using an ultrahigh-voltage transmission electron microscope. ${ }^{22)}$ Furthermore, the crack growth propagation 
along the dislocation substructure has been discussed for transgranular crack growth in Ti-bearing interstitial-free steel with dislocation cell structures. ${ }^{23)}$ The width of the striations observed in the fracture surface (Fig. 7(d)) and the size of the dislocation cells in the ECC image (Fig. 10) are both on the order of $1 \mu \mathrm{m}$. It was also previously reported ${ }^{23)}$ that striation patterns appear on the fracture surface when a crack propagates along the dislocation cell wall. Here again, we note the fact that The crack propagation perpendicular to the loading direction, which corresponds to the crack blunting/re-sharpening mechanism, occurred less frequently than in the HEA. This implies that, because the resistance to the fatigue crack growth due to the blunting/re-sharpening mechanism was higher in the HEA, a region with a high density of lattice defects (fatigue damage), such as dislocation walls, was selected as an alternative crack growth path.

\subsection{Relationship between Stacking Fault Energy (SFE) and Fatigue Crack Growth Rate}

The SFE is a factor affecting the fatigue crack growth characteristics. Fatigue crack opening is caused by dislocation emission from a crack tip. Materials with a low SFE are less susceptible to cross slip, which increases the work hardening capability. The work hardening at the crack tip prevents crack opening, reducing the fatigue crack growth rates in low-SFE materials. ${ }^{2425}$ ) The SFEs of the SUS316L and the HEA were $12.9 \mathrm{~mJ} / \mathrm{m}^{2}{ }^{26)}$ and $30 \pm 5 \mathrm{~mJ} / \mathrm{m}^{2},{ }^{27)}$ respectively. The SFE of the HEA was higher, which is consistent with the lower deformation-twin probability in the HEA compared with the SUS316L, as shown Fig. 10. Accordingly, the fatigue crack growth rate of the HEA should be higher than that of the SUS316L. However, the opposite result was obtained in this study. This indicates that factors other than the SFE affected the fatigue crack growth resistance in the HEA. In the future, we must clarify the unknown factors as well as the effect of the crack roughness on the fatigue crack growth in the HEA.

\section{Conclusions}

CT tests with the increase of $\Delta K$ were performed on an HEA and SUS316L at room temperature $\left(23^{\circ} \mathrm{C}\right)$, and the fatigue crack growth characteristics and associated deformation microstructure were investigated. The following results were obtained.

(1) The fatigue crack growth rate of the HEA was lower than that of the SUS316L. The difference in the fatigue crack growth rates between the two alloys was particularly significant at a low $\Delta K$.

(2) The fatigue crack growth path of the HEA was distinctly deflected compared with that of the SUS316L. That is, the effect of the roughness-induced crack closure was larger in the HEA than in the SUS316L.
(3) According to the fracture surface observation, the fatigue cracks of the HEA and the SUS316L propagated transgranularly, and a part of the fracture surface was a facet fracture surface. However, the area fraction of the fracture surface that exhibited a crystallographic character was low (approximately 9\%) in both alloys.

(4) Parts of the main and secondary transgranular deflected cracks were not along the slip plane. We propose that the cracks propagated along the dislocation cell-like microstructure near the crack tip.

\section{Acknowledgement}

This work was financially supported by JSPS KAKENHI (JP16H06365 and JP17H04956) and the Japan Science and Technology Agency (JST) (grant number: 20100113) under the Industry-Academia Collaborative R\&D Program.

\section{REFERENCES}

1) Y. Zhang, T. T. Zuo, Z. Tang, M. C. Gao, K. A. Dahmen, P. K. Liaw and Z. P. Lu: Prog. Mater. Sci., 61 (2014), 1.

2) B. Gludovatz, A. Hohenwarter, D. Catoor, E. H. Chang, E. P. George and R. O. Ritchie: Science, 345 (2014), 1153.

3) F. Otto, A. Dlouhy, Ch. Somsen, H. Bei, G. Eggeler and E. P. George: Acta Mater., 61 (2013), 5743.

4) A. Gali and E. P. George: Intermetallics, 39 (2013), 74.

5) B. Gludovatz, E. P. George and R. O. Ritchie: JOM, 67 (2015), 2262.

6) K. E. Nygren, K. M. Bertsch, S. Wang, H. Bei, A. Nagao and I. M. Robertson: Curr. Opin. Solid State Mater. Sci., 22 (2018), 1.

7) K. Ichii, M. Koyama, C. C. Tasan and K. Tsuzaki: Scr. Mater., 150 (2018), 74.

8) K. V. S. Thurston, B. Gludovatz, A. Hohenwarter, G. Laplanche, E. P. George and R. O. Ritchie: Intermetallics, 88 (2017), 65.

9) B. Cantor, I. T. H. Chang, P. Knight and A. J. B. Vincent: Mater. Sci. Eng. A, 375-377 (2004), 213.

10) ASTM E647: 2011, Standard Test Method for Measurement of Fatigue Crack Growth Rates.

11) S. Suresh: Fatigue of Materials, The Press Syndicate of the University of Cambridge, Cambridge, (1998), 483.

12) S. Suresh and R. O. Ritchie: Metall. Trans. A, 13 (1982), 1627

13) G. T. Gray, J. C. Williams and A. W. Thompson: Metall. Trans. A, 14 (1983), 421

14) M. Koyama, Z. Zhang, M. Wang, D. Ponge, D. Raabe, K. Tsuzaki, H. Noguchi and C. C. Tasan: Science, 335 (2017), 1055.

15) M. Koyama, Z. J. Xi, Y. Yoshida, N. Yoshimura, K. Ushioda and H. Noguchi: ISIJ Int., 55 (2015), 2463.

16) L. W. Tsay, J. J. Chen and J. C. Huang: Corros. Sci., 50 (2008), 2973.

17) Y. B. Ju, M. Koyama, T. Sawaguchi, K. Tsuzaki and H. Noguchi: Acta Mater., 112 (2016), 326.

18) K. Habib, M. Koyama and H. Noguchi: Int. J. Fatigue, 99 (2017), 1.

19) Y. Ro, S. R. Agnew and R. P. Gangloff: Metall. Mater. Trans. A, 38 (2007), 3042.

20) Y. B. Ju, M. Koyama, T. Sawaguchi, K. Tsuzaki and H. Noguchi: Int. J. Fatigue, 103 (2017), 533.

21) R. Koterazawa: Tetsu-to-Hagané, 70 (1984), 803 (in Japanese).

22) J. Awatani, K. Katagiri, H. Nakai, A. Omura and K. Koyanagi: $J$. Soc. Mater. Sci. Jpn., 27 (1978), 257 (in Japanese).

23) K. Ushioda, S. Goto, Y. Komatsu, A. Hoshino and S. Takebayashi: ISIJ Int., 49 (2009), 312.

24) J. Awatani, K. Katagiri and K. Koyanagi: Metall. Trans. A, 10 (1979), 503.

25) A. J. McEvily, Jr. and R. G. Boettner: Acta Metall., 11 (1963), 725.

26) M. Ojima, Y. Adachi, Y. Tomota, Y. Katada, Y. Kaneko, K. Kuroda and H. Saka: Steel Res. Int., 80 (2009), 477.

27) N. L. Okamoto, S. Fujimoto, Y. Kambara, M. Kawamura, Z. M. T. Chen, H. Matsunoshita, K. Tanaka, H. Inui and E. P. George: Sci. Rep., 6 (2016), 35863. 